\title{
Proactive coping in schizophrenia: examining the impact of neurocognitive variables
}

\section{Introduction}

Stress-vulnerability models of schizophrenia have long suggested that multiple confluent variables influence disease outcome, including individual vulnerability and environmental factors (Nuechterlein \& Dawson 1984). In general, people with schizophrenia tend to employ poor problem-solving strategies, are more likely to adopt passive coping styles, tend to use fewer types of coping strategies and have a propensity to avoid stressors (Thurm \& Haefner 1987, Wiedl 1992, Macdonald et al. 1998, Horan \& Blanchard 2003, Lysaker et al. 2003).

These tendencies have an adverse effect on symptoms, social functioning, quality of life and risk of relapse, particularly when patients face stressful life events (Norman \& Malla 1993, Horan et al. 2007).

Although the classical view of coping conceptualizes coping as a compensatory and reactive set of strategies in response to a stressor, a more positive, future-oriented and preventive means of coping, called proactive coping, has more recently been proposed (Greenglass 2002, Schwarzer 2004).

Proactive coping, a concept derived from the positive psychology movement, integrates processes of personal quality of life management and selfregulatory goal striving, encouraging individuals to view environmental demands as stimulating challenges rather than as stressors (Greenglass 2002, Greenglass et al. 2006). Proactive coping emphasizes the accumulation and mobilization of resources when needed and allows individuals to manage potential stressful events before they occur to promote personal growth in general and to enhance one's sense of self-determination (Greenglass et al. 2005, Greenglass \& Fiksenbaum 2009). Yanos \& Moos (2007) suggest that goal attainment and proactive coping are crucial for the achievement of positive outcomes in schizophrenia.

As a multidimensional process, proactive coping requires diverse abilities such as volition, planning, mental simulation, hypothesis generation, monitoring and intentional action according to a plan (Schwarzer 1999, Aspinwall 2005). For this reason, we hypothesize that proactive coping behaviours in schizophrenia depend on a patient's neurocognitive state. Deficits to a variety of cognitive functions may limit the rate at which people with schizophrenia can learn coping strategies and may also interfere with a patient's ability to form associations in order to do more than avoid difficulties in his/her daily life. Indeed, cross-sectional data indicate that neurocognitive impairment, particularly on measures of executive functioning, memory and sustained attention, predicts passive avoidance strategies and decreased preference for approachbased coping responses (WilderWillis et al. 2002, Lysaker et al. 2004, 2005, Ventura et al. 2004).

In the absence of severe life events, patients with fewer cognitive resources, as estimated by an electrophysiological measure (P300 amplitude), exhibited poorer adaptive coping skills and an elevated risk of relapse (Pallanti et al. 1997).

To date, however, no studies have examined the effects of neurocognition on proactive coping in people with schizophrenia. The purpose of the current study was to examine associations between neurocognitive measures and a variety of coping domains, with a primary focus on proactive coping.

\section{Methods}

The initial sample consisted of 37 stable patients recruited from three psychiatric institutions in northern Portugal with a DSM-IV diagnosis of schizophrenia.

The patients showed no evidence of mental retardation, organic brain diseases or drug/alcohol dependence. The study was approved by local directive boards. After the study aims and procedures were explained, the patients were required to provide written informed consent to participate.

From the initial sample, nine subjects abandoned the study during the follow-up period, resulting in a final sample of 28 participants. All of the participants were followed for no longer than 30 months between initial neurocognitive testing and the follow-up coping assessment [mean follow-up time was 25.4 months; standard deviation $(\mathrm{SD})=5.3]$.

All of the participants were assessed for neurocognitive function on the following domains: sustained attention (d2 Cancellation Test; Brickenkamp \& Zillmer 1998); perseveration and executive functioning (percentage of perseverative errors, Wisconsin Card Sorting Test; Heaton et al. 1993); processing speed (DigitSymbol-Coding and Symbol Search, Wechsler Adult Intelligence Scale - WAIS-III; Wechsler 1997); working memory (Digit Span and Letter-Number Sequencing, WAIS-III; Wechsler 1997); calculation (Arithmetic, WAIS-III; Wechsler 1997); visuo-spatial organization and memory (copy and immediate-recall conditions, Rey-Osterrieth complex figure test; Osterrieth 1944, Rocha \& Coelho 1988); and general intellectual ability (IA Test; Amaral 1966). These assessments were conducted by experienced research psychologists.

The Proactive Coping Inventory (PCI; Greenglass et al. 1999, Greenglass 2002) was used as a multidimensional assessment of coping. The PCI consists of 55 items measured on a 4-point Likert-type scale ranging from 'never' to 'always' and organized into seven separate scales. The PCI scales are as follows: (1) proactive coping (sample item: 'After attaining a goal, I look for another, more challenging one'); (2) reflective coping (sample item: 'I take action only after thinking carefully about a problem'); (3) strategic planning (sample item: 'I break down a problem into smaller parts and do one part at a time'); (4) preventive coping (sample item: 'I prepare for adverse 
events'); (5) instrumental support seeking (sample item: 'I can usually identify people who can help me develop my own solutions to problems'); (6) emotional support seeking (sample item: 'If I am depressed I know who I can call to help me feel better'); and (7) avoidance coping (sample item: 'If I find a problem too difficult sometimes I put it aside until I'm ready to deal with it').

Data were analyzed using Pearson product- moment correlations to determine associations between neurocognitive function and coping. In addition, stepwise multiple regression analysis was conducted to calculate the proportion of variance in different coping domains accounted for by neurocognitive variables. Neurocognitive scores were entered as predictor variables, and PCI scales served as dependent variables. A probability of 0.05 was used to enter a variable in the equation, while a probability of 0.10 was used to remove a variable.

Statistical analyses were carried out using IBM SPSS Statistics 19 (IBM Corporation, Armonk, NY, USA).

\section{Results}

The mean age of the 28 participants at study entry was 42.6 years $(\mathrm{SD}=8.2)$, and the mean education was 8.5 years $(\mathrm{SD}=4.4)$. Most of the participants were male $(n=26)$, and the distribution of marital status was as follows: 20 single, 2 married and 6 divorced.With regard to employment status, 3 were employed, 3 were unemployed and 22 were receiving disability benefits. Most of the participants were living in community residences $(n=16)$, eight lived in their parents' home and four lived independently in their own houses. The mean Brief Psychiatric Rating Scale score was 39.3 (SD = 12.2). A total of 13 were being treated with atypical antipsychotics, 8 with typical antipsychotics and 7 with both typical and atypical antipsychotics.

Significant associations were observed between nearly all neurocognitive factors and the proactive and reflective coping scales of the PSI (Table 1).

Only the percentage of perseverative errors on the Wisconsin Card Sorting Test was not significantly correlated with any PCI scale. Digit Span and the IA Test were significantly associated with all of the PCI scales except the avoidance coping scale, which was not significantly correlated with any neurocognitive factor. Digit Symbol-Coding and Symbol Search were significantly correlated with preventive coping $(r=.44$ and $r=$ .41 , respectively; $P<.05)$, and the former was also associated with instrumental support seeking $(r=.39 ; P<$ .05). Letter-Number Sequencing was correlated with preventive coping $(r=.47 ; P<.05)$, and arithmetic was associated with preventive coping $(r=.43 ; P<.05)$, instrumental support seeking $(r=.48 ; P<.05)$ and emotional support seeking $(r=.51 ; P<.01$, respectively).

Regarding the Rey-Osterrieth complex figure test, there were significant relationships between scores on the copy condition and the Strategic Planning and Preventive Coping scales of the PCI ( $r=.46$ and $r=.48$, respectively; $P<.05)$ and between the recall condition and the strategic planning $(r=.54 ; P<$ $.01)$, preventive coping $(r=.41 ; P<.05)$ and instrumental support seeking scales $(r=.45 ; P<.05)$. 


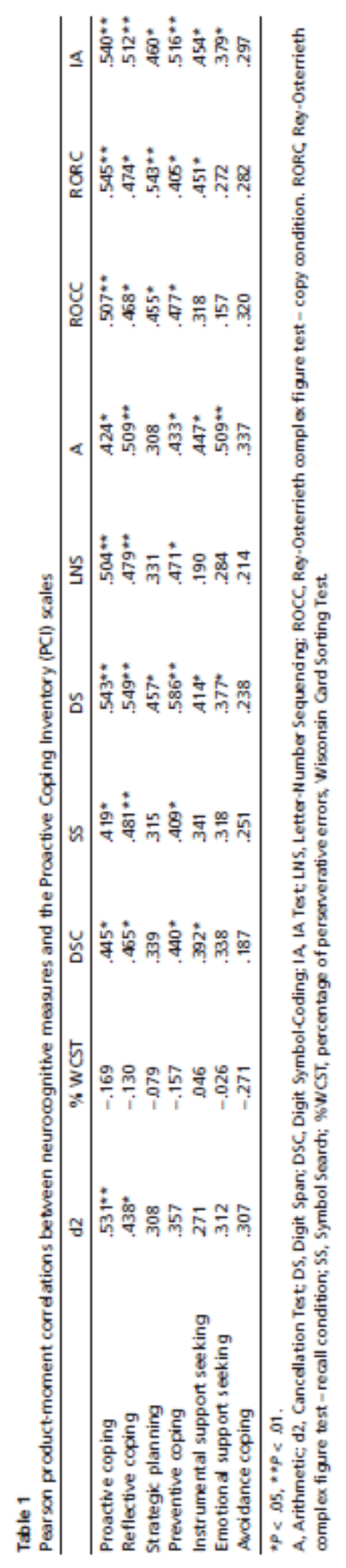

After Pearson correlation coefficients were calculated, stepwise multiple regressions were conducted to identify the best combination of neurocognitive variables for predicting coping ability and to calculate the amount of variance accounted for by neurocognitive variables. The Rey-Osterrieth complex figure test - recall condition and Digit Span were significant predictors of proactive coping $\left(r_{2}=.43, F=9.48, P<.01\right)$, reflective coping $\left(r_{2}\right.$ $=.39, F=7.84, P<.01)$ and strategic planning $\left(r_{2}=.37, F=7.32, P<.01\right)$. Digit Span predicted preventive coping $\left(r_{2}=.34, F=8.51, P<.01\right)$, the Rey-Osterrieth complex figure test - recall condition predicted instrumental support seeking $\left(r_{2}=.20, F=7.32, P<.05\right)$ and arithmetic predicte emotional support seeking $\left(r_{2}\right.$ $=.26, F=9.08, P<.01)$. 


\section{Discussion}

To our knowledge, this is the first study to find that neurocognitive abilities are associated with proactive coping in schizophrenia. The current data also demonstrate that a variety of neurocognitive factors are associated with different coping attitudes, which collectively allow for the flexible consideration of alternatives, generation of goal-oriented plans, anticipation of threats and utilization of social resources.

These results are consistent with previous findings that observed that the use of active coping strategies is correlated with neuropsychological testing results (Wilder-Willis et al. 2002, Lysaker et al. 2004, 2005, Ventura et al. 2004) and, in a broader sense, with studies relating neurocognitive deficits to functional outcomes (Green et al. 2000, 2004).

In particular, we found that two memory tests (Digit Span and the Rey-Osterrieth complex figure test recall condition) were strongly linked to the use of proactive, reflective, preventive and strategic coping skills and to the use of social resources for instrumental purposes. The Digit Span (Wechsler 1997) is a measure of working memory capacity in which participants must immediately repeat numbers in the given order of presentation (forward condition) or in reverse order (backward condition).

The Rey-Osterrieth complex figure test - recall condition (Osterrieth 1944, Rocha \& Coelho 1988) assesses visuo-spatial organization and memory by asking the participant to reproduce a complex figure from memory.

In other studies, working memory and visual memory have been associated with social and community functioning (Kopelowicz et al. 2005, Prouteau et al. 2005). Additionally, memory impairments can result in less adaptive coping mechanisms in patients with schizophrenia (Wilder-Willis et al. 2002, Lysaker et al. 2004, 2005).

Proactive coping - as well as other forms of coping that involve prevention, consideration of alternatives and mobilization of resources when needed - requires that an individual correctly register actions already taken, thus allowing for the generation and selection of an appropriate goaloriented course of action. This form of coping may also require the effective storage and recall of significant information related to observed and experienced strategies and actions, which may prove useful in a specific situation.

As discussed by Lysaker et al. (2004), visual memory may be an important factor in this ability.

Intact visual memory enables one to create a mental picture of actions one might take to confront an existing stressor or prevent a potential stressor or to obtain help or support from other people. The ability to hold and manipulate information in memory may also help one to picture future events. This may be an important skill for adaptive coping given that the ability to create vivid mental images of the future is associated with positive affect and well-being (Holmes et al. 2008, 2009, Blackwell et al. 2013).

We expected to see significant negative correlations between neurocognitive test scores and avoidance coping because it is commonly accepted that the use of avoidant strategies is common in patients with fewer cognitive resources. One reason for the absence of significant associations is that the avoidance coping scale of the PCI does not reflect behaviours related to escape or avoidance of problems.

Rather, this scale reflects one's tendency to wait, reflect and see things more clearly before directly dealing with a problem, which may not require high levels of neurocognitive functioning.

Another unexpected result was the absence of significant associations between executive functioning, as measured by the WCST and PCI scales.

Although a previous study also failed to identify associations between executive functioning and coping (Bak et al. 2008), the coping mechanisms investigated in this study were expected to be highly demanding higher cognitive functions. One possible explanation for these findings is that we only considered perseverative errors as an indicator of executive functioning. We may have observed different results if we had also included measures of executive functioning focused on planning, problem solving and flexibility.

This study has implications for mental health nurses and other mental health practitioners involved in psychiatric rehabilitation. In fact, the coping abilities of people with severe mental illnesses are considered to be an important dimension of mental health care in general and of psychiatric nursing in particular (Rudnick \& Martins 2009).

The psychiatric rehabilitation process aims to restore appropriate functioning in people with severe mental illness by developing skills and/or supports (Anthony \& Farkas 2009). Skills taught during psychosocial interventions often involve coping skills necessary to live as independently as possible in the community. Our findings suggest that mental health practitioners can facilitate adaptive coping by promoting and restoring cognitive functioning.

Antipsychotic medications are not sufficient to effectively address cognitive deficits that may disturb proactive coping abilities in schizophrenia (Daban et al. 2005). The restoration of cognitive impairments or the acquisition of compensatory strategies is generally more effective using cognitive remediation (Wykes et al. 2011). Based on the current findings, we suggest that improving cognition by means of cognitive remediation might be used as a way to promote adaptive proactive coping in a psychiatric care setting.

This study has a number of limitations. First, the PCI is a subjective self-report measure, which may raise doubts about the validity of a participant's report. Second, the sample size was relatively small, limiting the power of the multivariate analyses conducted. 
Third, there were differences in the time between participants' two study visits. However, these time differences were kept relatively small, and one of the strengths of this study was that data were collected prospectively.

\section{N. ROCHA PhD}

Professor

Instituto Politécnico do Porto - Escola Superior de Tecnologia da Saúde; Universidade do Porto - Faculdade de Psicologia e de Ciências da Educação, Porto, Portugal

\section{A. J. MARQUES PhD}

Professor

Instituto Politécnico do Porto - Escola Superior de Tecnologia da Saúde; Universidade do Porto - Faculdade de Psicologia e de Ciências da Educação, Porto, Portugal

C. QUEIRÓS PhD

Professor

Universidade do Porto - Faculdade de Psicologia e de Ciências da Educação, Porto, Portugal

S. ROCHA MSC

Lecturer

Instituto Politécnico do Porto - Instituto Superior de Contabilidade e Administração do Porto, Porto, Portugal

\section{References}

Amaral J. (1966) Aferição do Teste IA (Escala Reduzida das Matrizes Progressivas de J. C. Raven). Centro de Estudos Psicopedagógicos Escola Técnica Eugénio dos Santos, Lisboa.

Anthony W. \& Farkas M. (2009) A Primer on the Psychiatric Rehabilitation Process. Center for Psychiatric Rehabilitation, Boston, MA

Aspinwall L. (2005) The psychology of future-oriented thinking: from achievement to proactive coping, adaptation, and aging. Motiv Emotion 29, 203235.

Bak M., Krabbendam L., Delespaul P., et al. (2008) Executive function does not predict coping with symptoms in stable patients with a diagnosis of schizophrenia. BMC Psychiatry 8, 39.

Blackwell S.E., Rius-Ottenheim N., Schulte-van Maaren Y.W., et al. (2013) Optimism and mental imagery: a possible cognitive marker to promote wellbeing? Psychiatry Research 206, 56-61.

Brickenkamp R. \& Zillmer E. (1998) The d2 Test of Attention. Hogrefe \& Huber Publishers, Seattle, WA

Daban C., Amado I., Bourdel M.C., et al. (2005) Cognitive dysfunctions in medicated and unmedicated patients with recent-onset schizophrenia. Journal of Psychiatric Research 39, 391-398.

Green M., Kern R., Braff D., et al. (2000) Neurocognitive deficits and functional outcome in schizophrenia: are we measuring the 'right stuff'? Schizophrenia Bulletin 26, 119-136.

Green M., Kern R. \& Heaton R. (2004) Longitudinal studies of cognition and functional outcome in schizophrenia: implications for MATRICS. Schizophrenia Research 72, 41-51.

Greenglass E. (2002) Proactive coping, Chapter 3. In: Beyond Coping: Meeting Goals, Vision, and Challenges (ed Frydenberg E.), pp. 37-62. Oxford University Press, London.

Greenglass E. \& Fiksenbaum L. (2009) Proactive coping, positive affect and well-being: testing for mediation using path analysis. Eur Psychologist 14, 29-39.

Greenglass E., Schwarzer R., Jakubiec D., et al. (1999) The Proactive Coping Inventory (PCI): A Multidimensional Research Instrument. In: 20th International Conference of the Stress and Anxiety Research Society, Cracow, Poland.

Greenglass E., Marques S., deRidder M., et al. (2005) Positive coping and mastery in a rehabilitation setting. International

Journal of Rehabilitation Research 28, 331-339.

Greenglass E., Fiksenbaum L. \& Eaton J. (2006) The relationship between coping, social support, functional disability and depression in the elderly. Anxiety Stress Coping 19, 15-31.

Heaton R., Chelune G., Talley J., et al. (1993) Wisconsin Card Sorting Test Manual: Revised and Expanded. Psychological Assessment Resources, Odessa, FL.

Holmes E.A., Coughtrey A.E. \& Connor A. (2008) Looking at or through rose-tinted glasses? Imagery perspective and positive mood. Emotion (Washington, D.C.) 8, 875-879.

Holmes E.A., Lang T.J. \& Shah D.M. (2009) Developing interpretation bias modification as a 'cognitive vaccine' for depressed mood: imagining positive events makes you feel better than thinking about them verbally. Journal of Abnormal Psychology 118, 76-88.

Horan W. \& Blanchard J. (2003) Emotional responses to psychosocial stress in schizophrenia: the role of individual differences in affective traits and coping. Schizophrenia Research 20, 271-283

HoranW., Ventura J., Mintz J., et al. (2007) Stress and coping responses to a natural disaster in people with schizophrenia. Psychiatry Research 151, 7786.

Kopelowicz A., Liberman R., Ventura J., et al. (2005) Neurocognitive Correlates of Recovery from Schizophrenia. Psychological Medicine 35, 11651173

Lysaker P., Wilt M., Plascek-Hallberg C., et al. (2003) The association of personality with symptoms and coping in schizophrenia. The Journal of Nervous and Mental Disease 191, 80-86.

Lysaker P., Bryson Q., Marks K., et al. (2004) Coping style in schizophrenia: associations with neurocognitive deficits and personality. Schizophrenia Bulletin 30, 113-121.

Lysaker P., Davis L., Lightfoot J., et al. (2005) Association of neurocognition, anxiety, positive and negative symptoms with coping preference in schizophrenia spectrum disorders. Schizophrenia Research 80, 163-171.

Macdonald E., Pica S., McDonald S., et al. (1998) Stress and coping in early psychosis. The British Journal of Psychiatry: The Journal of Mental Science 172 (Suppl. 33), 122-127.

Norman R. \& Malla A. (1993) Stressful life events and schizophrenia I: a review of the research. The British Journal of Psychiatry: The Journal of Mental Science 162, 161-166.

Nuechterlein K. \& Dawson M. (1984) A heuristic vulnerability/stress model of schizophrenic episodes. Schizophrenia Bulletin 10, $204-232$.

Osterrieth P. (1944) Le test de copie d'une figure complex: contribution à l'étude de la perception et de la memoire. Arch Psychol 30, 286-350.

Pallanti S., Quercioli L. \& Pazzagli A. (1997) Relapse in young paranoid schizophrenic patients: a prospective study of stressful life events, P300 meas ures, and coping. The American Journal of Psychiatry 154, 792-798. 
Prouteau A., Verdoux H., Briand C., et al. (2005) Cognitive predictors of psychosocial functioning outcome in schizophrenia: a follow-up study of subjects participating in a rehabilitation program. Schizophrenia Research 77, 343-353.

Rocha A. \& Coelho M. (1988) Teste de Cópia de Figuras Complexas: Manual. CEGOC-TEA, Lisboa.

Rudnick A. \& Martins J. (2009) Coping and schizophrenia: a re-analysis. Archives of Psychiatric Nursing 23, 11-15.

Schwarzer R. (1999) Self-regulatory processes in the adoption and maintenance of health behaviors. Journal of Health Psychology 4, 115-127.

Schwarzer R. (2004) Manage stress at work through preventive and proactive coping. In: The Blackwell Handbook of Principles of Organizational Behavior (ed Locke E.), pp. 342-355. Blackwell Publishing, Oxford, UK.

Thurm I. \& Haefner H. (1987) Perceived vulnerability, relapse risk and coping in schizophrenia. An explorative study. European Archives of Psychiatry and Neurological Sciences 237, 46-53.

Ventura J., Nuechterlein K., Subotnik K., et al. (2004) Self-efficacy and neurocognition may be related to coping responses in recent-onset schizophrenia. Schizophrenia Research 69, 343-352.

Wechsler D. (1997) Wechsler Adult Intelligence Scale, 3rd edn. Psychological Corporation, San Antonio, TX.

Wiedl K. (1992) Assessment of coping with schizophrenia: stressors, appraisals and coping behaviour. The British Journal of Psychiatry: The Journal of Mental Science 161 (Suppl. 18), 114-122.

Wilder-Willis K., Shear P., Steffen J., et al. (2002) The relationship between cognitive dysfunction and coping abilities in schizophrenia. Schizophrenia Research 55, 259-267.

Wykes T., Huddy V., Cellard C., et al. (2011) A meta-analysis of cognitive remediation for schizophrenia: methodology and effect sizes. American Journal of Psychiatry 168, 472-485.

Yanos P. \& Moos R. (2007) Determinants of functioning and well-being among individuals with schizophrenia: an integrated model. Clinical Psychology Review 27, 58-77. 